\title{
Failure Prediction of Highly Requested Complex Technical Systems: Application to W18v50df Engines
}

\author{
Florence OFFOLE, Dieudonné ESSOLA, Nelson ISSONDJ and Charly BOUHEUL
}

Research Scholars

Department of Automobile Technology

Faculty of Industrial Engineering

University of Douala

Cameroon

\begin{abstract}
The work done in this paper has focused on the prediction of failures of a complex and highly stressed technical system for energy production, namely the W18V50DF engine powering an MW gas-fired power plant. The aim of this work is to highlight the prediction curves, a priori and a posteriori, of the evolution (probabilistic) of the state of these W18V50DF engines in order to anticipate the appearance of a failure and to put a human machine interface to facilitate the knowledge of a possible event and to allow a remote action. To do this, a hybrid method has been employed in the field of data-oriented modeling which highlights the neural network modeling used to determine the state of the components of the system studied by classification. Coupled with Bayesian network modeling, also known as probabilistic graphical models used to predict the state of the system. The neural model and the HMI have been built respectively through the ntools library and via the GUIDE library of the MATLAB software, while the probabilistic graphical model has been built using the BayesianLab software. The work carried out has shown that the W18V50DF engine and its components are degraded as their lifetimes evolve. In addition, because of its complexity and the criticality of some of its components, the degradation of the W18V50DF engine will be accelerated as each of them will be. In addition to this, the financial evaluation revealed that this work, beyond its multiple technical challenges, would allow the user to make significant financial gains.
\end{abstract}

Key Words: Prediction, Failures, Complex Technical Systems, W18V50DF Engine, Neural Networks, Bayesian Networks.

\section{INTRODUCTION}

The increasingly complex nature of industrial systems [1], coupled with the constraints of competitiveness and current legislation [2] which tend to be the same for all in terms of respect for the environment, brings producers, users and the scientific community to look for solutions that can make these systems more efficient [3], more competitive and safer [4]. One of the points on which the research work is directed is the forecasting [1] in which work is carried out on the diagnosis and the prognosis of failures. Thanks to the technological progress of the last decades, the acquisition of massive operating data of industrial machines has become easy [3] which has facilitated the race for several domains of artificial intelligence in the era of the democratization of microprocessors and embedded systems [5]. Thus, the use of such systems in the service of the diagnosis and / or the prognosis of machine failures to the industry to improve their availability is strongly desired [6]. Prior to this, the diagnosis of failures was a task performed generally by expert humans and the prognosis was a mystery [7].

The gas plant considered is one of the largest in one sub-region of sub-Saharan Africa and has 13 engines dual fuels W18V50DF, on the horizon is expected to expand in order to achieve its objectives in terms of production so to remain faithful to its policy of continuous growth and customer satisfaction. These highly complex and very large equipment pose serious problems for the plant maintenance division. In order to improve its process, to have a better control of these state-of-the-art equipment, to limit the expenses related to the exploitation and the maintenance of these and to tie to the evolution more and more rapid technology, it is imperative to perform the failure prediction W18V50DF engines of this plant. To achieve the above objective, 
knowledge of the constituent elements of the studied system is necessary. It's about studying the inputs and outputs of the system, and trying to model logical relationships that exist between them.

\subsection{Concept Complex Technical System}

A system is defined in [8] as being a set of elements in relation to each other in such a way that any evolution of one causes a revolution of the whole and that any modification of the whole reacts on each one element. Thus, a system is determined by the nature of its constituent elements, the interactions between them and its boundary [8,9].

NFE 90-001 defines a technical system as a set of elements that are logically interconnected and coordinate to perform a specific task. If, moreover, this set of interconnected elements consists of a large number of interacting entities that prevent the observer from predicting his feedback, his behavior or evolution by calculation, this system is called complex technical system [9].

The difficulty in complex systems lies therefore in the way of apprehending them as a whole and not by the components constituting them because the properties they present as a whole do not necessarily come from each of the properties of the components constituting them. Examples of complex technical systems include: vehicles, planes, robotic production lines, turbo expanders, marine engines and industrial engines, among which are the dual fuels engines. In the rest of this work, we are only interested in the technology of W18V50DF duals fuels engines.

\subsection{Description and function of dual-fuel engines $W 18 V 50 D F$}

The W18V50DF engines are 18-cylinder engines built on 2 banks of 9 cylinders each arranged in a $\mathrm{V}$ configuration, operating in dual-fuel mode and providing a power of 16.6 MW [11, 12].

The characteristics and modes of operation of the engine are given respectively in Tables 1 and 2 and those of the fuels are given in the appendix.

Table 1: Engine characteristics

\begin{tabular}{|l|l|l|l|}
\hline Elements & Dimension & Elements & Dimension \\
\hline Bore & $500 \mathrm{~mm}$ & BMEP & $20 \mathrm{bars}$ \\
\hline Piston stroke & $580 \mathrm{~mm}$ & Piston speed & $9.7 \mathrm{~m} / \mathrm{s}$ \\
\hline $\begin{array}{l}\text { Crankshaft } \\
\text { rotation speed }\end{array}$ & $500 \mathrm{trs} / \mathrm{mn}$ & Power $/$ cylinder & $950 \mathrm{~kW}$ \\
\hline
\end{tabular}

Table 2: different modes of operation of W18V50DF motors

\begin{tabular}{|c|l|c|c|c|c|}
\hline \multicolumn{2}{|c|}{} & \multicolumn{3}{c|}{ Fuels (orifice of the injector) } & \multirow{2}{*}{ oxidizer } \\
\cline { 2 - 5 } \multicolumn{2}{|c|}{ mode } & Gas (principal) & LFO (principal) & LFO (pilot) & \\
\cline { 2 - 5 } & Diesel & $99 \%$ & & $1 \%$ & air \\
\cline { 2 - 5 } & backup & - & $99 \%$ & $1 \%$ & - \\
\hline
\end{tabular}

For its operation, the engine needs its auxiliary equipment. These have the role of supplying the engine with fluid necessary for the proper functioning of the engine. They are used for fuel on the one hand to regulate their pressures, filter them to remove impurities, heat them to remove condensates and reduce their viscosity and, on the other hand, to lubricate mechanical parts to reduce accelerated wear, cool hot engine parts, control electromechanical devices and engine start. They allow engine management and regulate modes and transitions as shown in Figure 1 below. These are the gas circuit, the LFO (Ligth Fuel Oil) circuit, the lubrication system and finally the instrumentation and starting air.

Table 3 of WECS 8000 activities

\begin{tabular}{|l|l|l|l|}
\hline № & \multicolumn{1}{|c|}{ WECS activities } & № & WECS activities \\
\hline 1 & $\begin{array}{l}\text { Management of slow rotation, start } \\
\text { and stop sequences }\end{array}$ & 7 & Control of gas pressure and gas inlet \\
\hline 2 & Changing fuel modes & 8 & Instrumentation and communication \\
\hline 3 & Cylinder balancing and knock control & 9 & Pilot pressure and pilot injection control \\
\hline 4 & Speed measurement & 10 & Air / fuel ratio control \\
\hline 5 & Engine safety & 11 & Speed / load control \\
\hline 6 & Diagnostic & & \\
\hline
\end{tabular}


The combustion management in the W18V50DF engines is done by the integrated motor management system designed for aggressive environments WECS 8000. To do this requires the presence of electronic modules that communicate with each other on the CAN bus. The system collects signals from various sensors located at various locations on the motor, locally connected to the modules. The received signals are processed and compared with the control parameters given for all the active processes of the motor. The main categories of WECS 8000 activities are classified in Table 3.

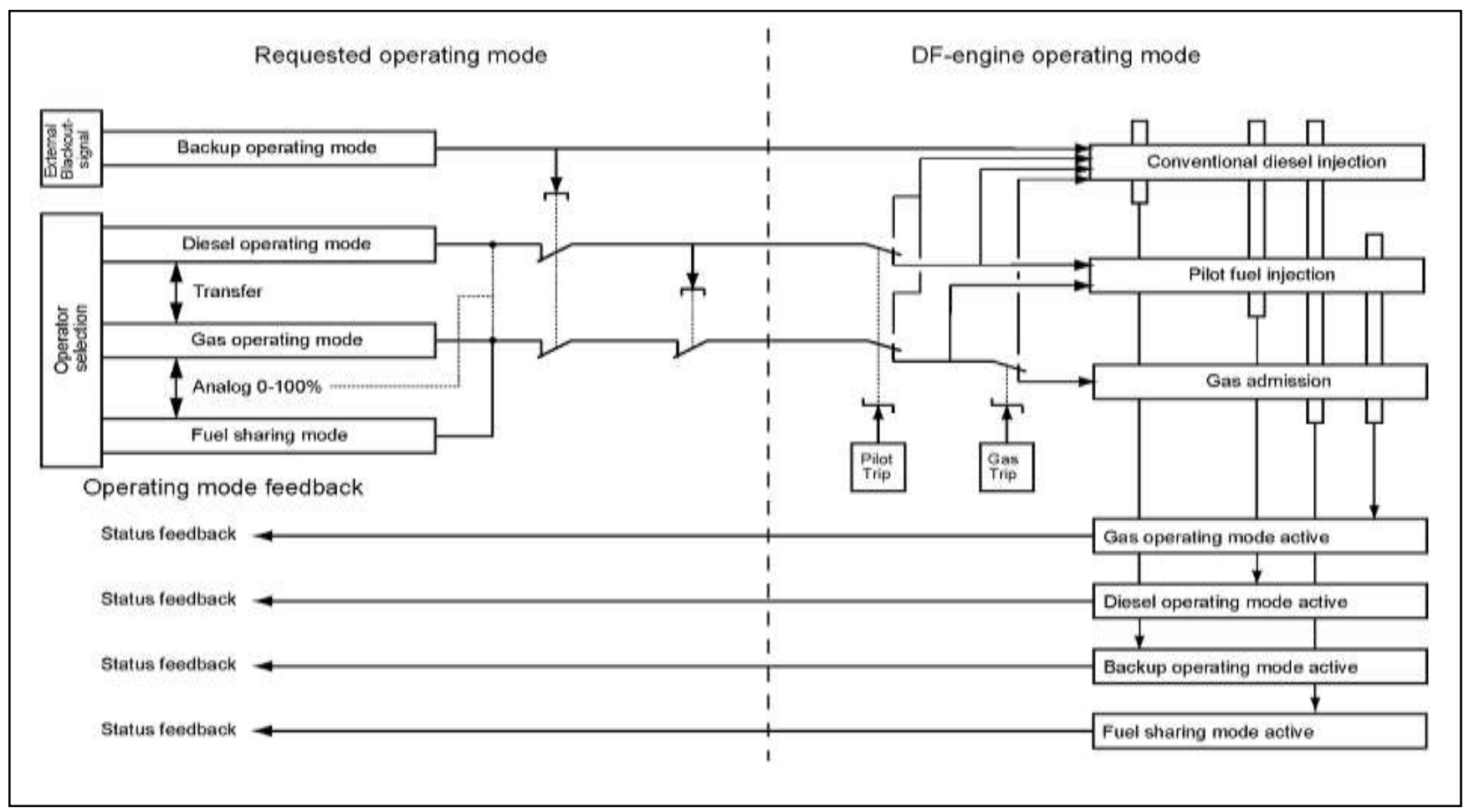

Figure 1: Different modes of operation and different possible transitions

The modules communicate with each other on a communication bus, and this communication is based on the CAN protocol.

The MCM 700 main control modules are two in number. The MCM-700-1 is the master of the WECS 8000 system. It deals with the processing of all the strategic control functions of the engine. The main processes are the start and stop sequences, the safety of the engine and the control of the combustion. It includes internal algorithms that, depending on the speed of rotation and the load, calculate the gas inlet and pilot injection pressures, the angle of the crankshaft at which the injections are made. It processes the signals sent by the other modules and sends reference signals to the control modules of the cylinders and communicates with the systems outside the engine itself. The MCM-700-2 only collects sensor signals for the control of the relief valve.

The control modules of the cylinders CCM 10. There are eight on one engine. Each CCM10 controls three cylinders. They control the gas intake and pilot fuel injection valves through PWM (Pulse Width Modulation) outputs. The local control panel on the engine, where most engine measurements and conditions can be controlled, and where the local pushbuttons and selectors are located. To view the motor parameters, a local display unit (LDU) is used, with a number of menus and menu selection buttons. As local push buttons and selectors, there are start, stop, emergency stop restore, remote / local, load increase / decrease and emergency stop buttons.

\subsection{Failures in W18V50DF motors}

In the $\mathrm{W} 18 \mathrm{~V} 50 \mathrm{DF}$ engines there is a variety of failures observed, the main consequence of which is the reduction of power at the motor output. According to the terminology of the manufacturer [11] and in relation to those observed, they can be classified as follows:

- Gas trips, which are failures that result in a switchover from gas mode to diesel mode without affecting the pilot fuel system. We can mention among others the "gas trip engine load swing" or the "gas trip low exhaust gas temperature deviation from reference". 
- Pilot trips" are failures on the pilot fuel circuit resulting in a switchover of the engine in conventional diesel mode (Backup). We can mention among others the pilot trip safety wireloop status or the pilot trip low pilot fuel pressure pump outlet.

Other failures that do not cause the motor to tilt can lead to a direct engine stop (overspeed, vibration of the crankshaft in torsion), a failure to start or a limitation of the engine performance.

An Ishikawa diagram analysis of the motor coupled with the Pareto diagram revealed the main classes of failures, the element responsible for this motor and its impact on engine operation.

In the W18V50DF engines there is a variety of failures observed, the main consequence of which is the reduction of power at the motor output. According to the terminology of the manufacturer [11] and in relation to those observed, they can be classified as follows:

- Gas trips, which are failures that result in a switchover from gas mode to diesel mode without affecting the pilot fuel system. We can mention among others the "gas trip engine load swing" or the "gas trip low exhaust gas temperature deviation from reference".

- Pilot trips" are failures on the pilot fuel circuit resulting in a switchover of the engine in conventional diesel mode (Backup). We can mention among others the pilot trip safety wireloop status or the pilot trip low pilot fuel pressure pump outlet.

Other failures that do not cause the motor to tilt can lead to a direct engine stop (overspeed, vibration of the crankshaft in torsion), a failure to start or a limitation of the engine performance.

An Ishikawa diagram analysis of the motor coupled with the Pareto diagram revealed the main classes of failures, the element responsible for this motor and its impact on engine operation.

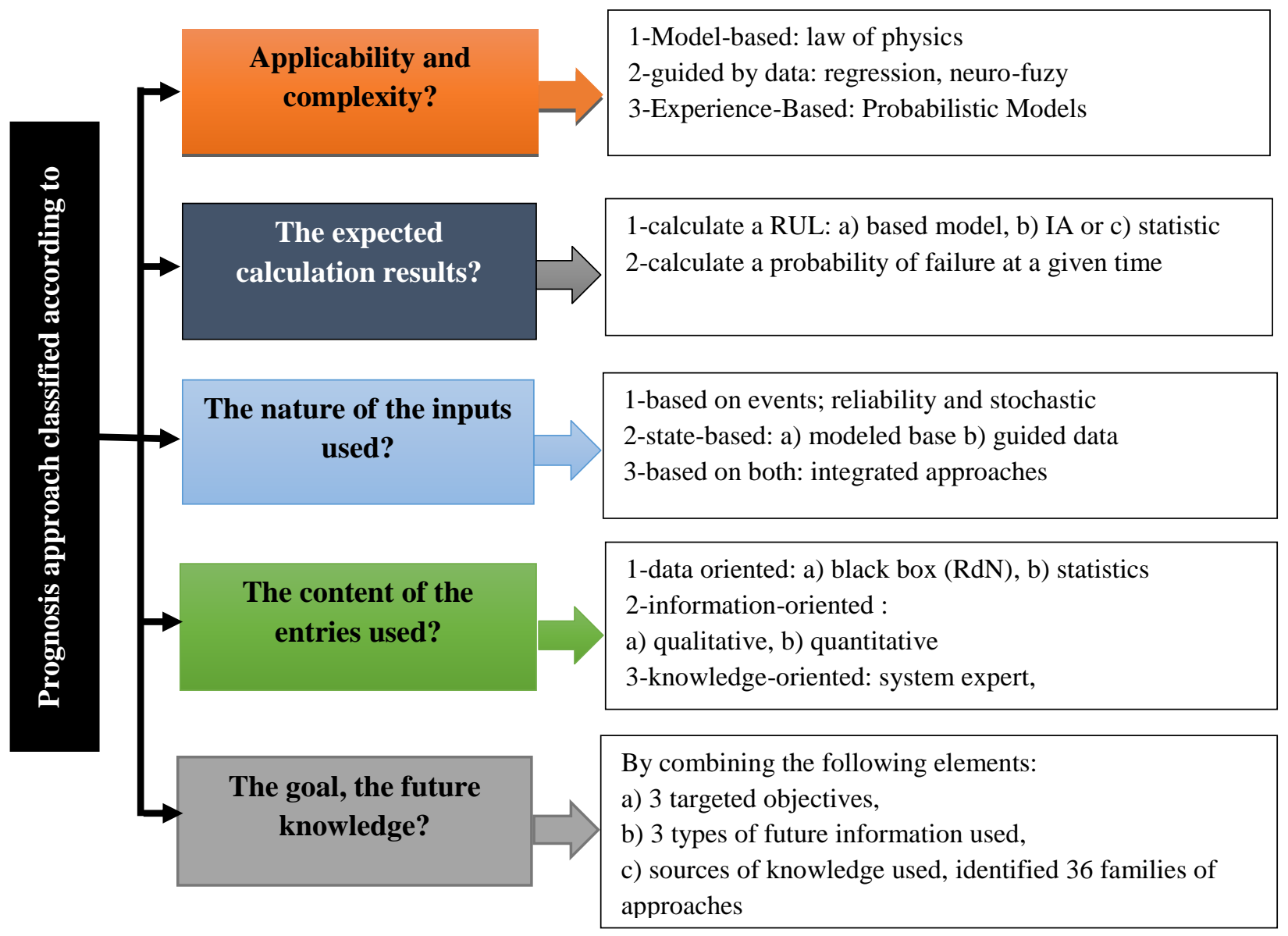

Figure 2: Criteria for classifying prognostic approaches 
The first classification is a ranking according to the domain of applicability and the complexity (cost and precision) resulting. As a result, both data-driven and experiential-based approaches are the most widely used in industry because it is not always easy to develop a physics-based model and it is relatively difficult to mathematically represent the evolution of degradation [14].

A new classification criterion has been proposed or the authors put forward the expected results following a prognostic process [15]. Note that approaches to determine the remaining life of a system (RUL) can be divided into three sub-families equivalent to the first classification: model-based approaches, data-driven approaches (artificial intelligence techniques) and approaches based on experience (techniques derived from statistics).

In contrast to this method, we find the classification criterion by examining the inputs used by a prognostic process [16]. Depending on the nature of these entries, the models are based on either events, states, or both. Similarly, the resulting subfamilies of this classification can be projected on the first classification: model-based and data-oriented approaches (state-type inputs) and experience-based approaches (event-type inputs).

. In the same logic, there is another criterion considering the content of the inputs used by a prognostic process. In the sense that a raw data does not bring information and that information is not necessarily knowledge [17]. This classification brings together, in a first family, approaches that deal with raw data either by statistical techniques or by neural networks (black boxes). If the data makes sense we are talking about information, in this case qualitative reasoning from cases, estimators or quantitative observers can be applied. The third family encompasses knowledge-based approaches, such as expert systems and decision trees.

The last proposed classification [18] is based on three criteria. The first specifies the purpose for which maintenance is performed: i) to ensure the reliability of the system, ii) to ensure reliability at the component level or iii) to ensure performance. The second criterion concerns the use of the future context: i) no use, ii) use operational and / or environmental conditions or iii) use a maintenance scenario. As for the last criterion, it distinguishes the origin of the knowledge used: i) comes from the laws of physics, ii) from the data, iii) combines the laws of physics and data or iv) knowledge resulting from the return of experience and data.

Thus, the chosen approach consists of a hybrid method in the field of data-oriented modeling, neuron network modeling (for the determination of state of the sensitive components of the system) coupled to the modeling by Bayesian networks or probabilistic graphical models (for the prediction of the state of the system) and the implementation of an HMI via the MATLAB software.

The objective of this work is to highlight the prediction curves, a priori and a posteriori, of the evolution (probabilistic) of the state of the system in order to be able to anticipate the appearance of a failure and put on foot an HMI to facilitate handling. This will make it possible to have a better control of these equipments, to limit the expenses related to the exploitation and the maintenance of these and to tie in with the evolution more and more fast of the technology for these highly complex equipments and very large, which poses serious problems for the maintenance division of the plant generating huge expenses

\section{MATERIAL AND METHODOLOGY}

\subsection{Working hypotheses}

For the conduct of this work, it will be useful to formulate the hypotheses for a better adequacy with the problem posed, the available data and the operational constraints. As an assumption, we will consider that:

- all engines are perfectly identical, ie the observations made on an engine or on one of its components will be considered as applicable to all other engines and / or their components.

- the dynamic changes are caused by a stationary process that is to say that the probabilities do not change in time: $\mathrm{P}$ (Xt $\mid$ Parent $(\mathrm{Xt})$ ) is the same for all $\mathrm{t}$ in order to limit the number of tables of probabilities of each variable in each state.

- dynamic changes are caused by a Markov process: the current state depends only on a finite number of previous states in order to limit the number of parents of the target node. Markovian processes of the first order:

$$
P\left(X_{t} \mid X_{0: t-1}\right)=P\left(X_{t} \mid X_{t-1}\right)
$$

- the evidence depends only on the current state.

$P\left(E_{t} \mid X_{0: t}, E_{0: t-1}\right)=P\left(E_{t} \mid X_{t}\right)$ number of parents of the parent target node of the transition elements.

\subsection{Prognostic procedure}

To make the prognosis of the studied system, an approach has been implemented whose steps are summarized in figure 3 opposite and described below. 


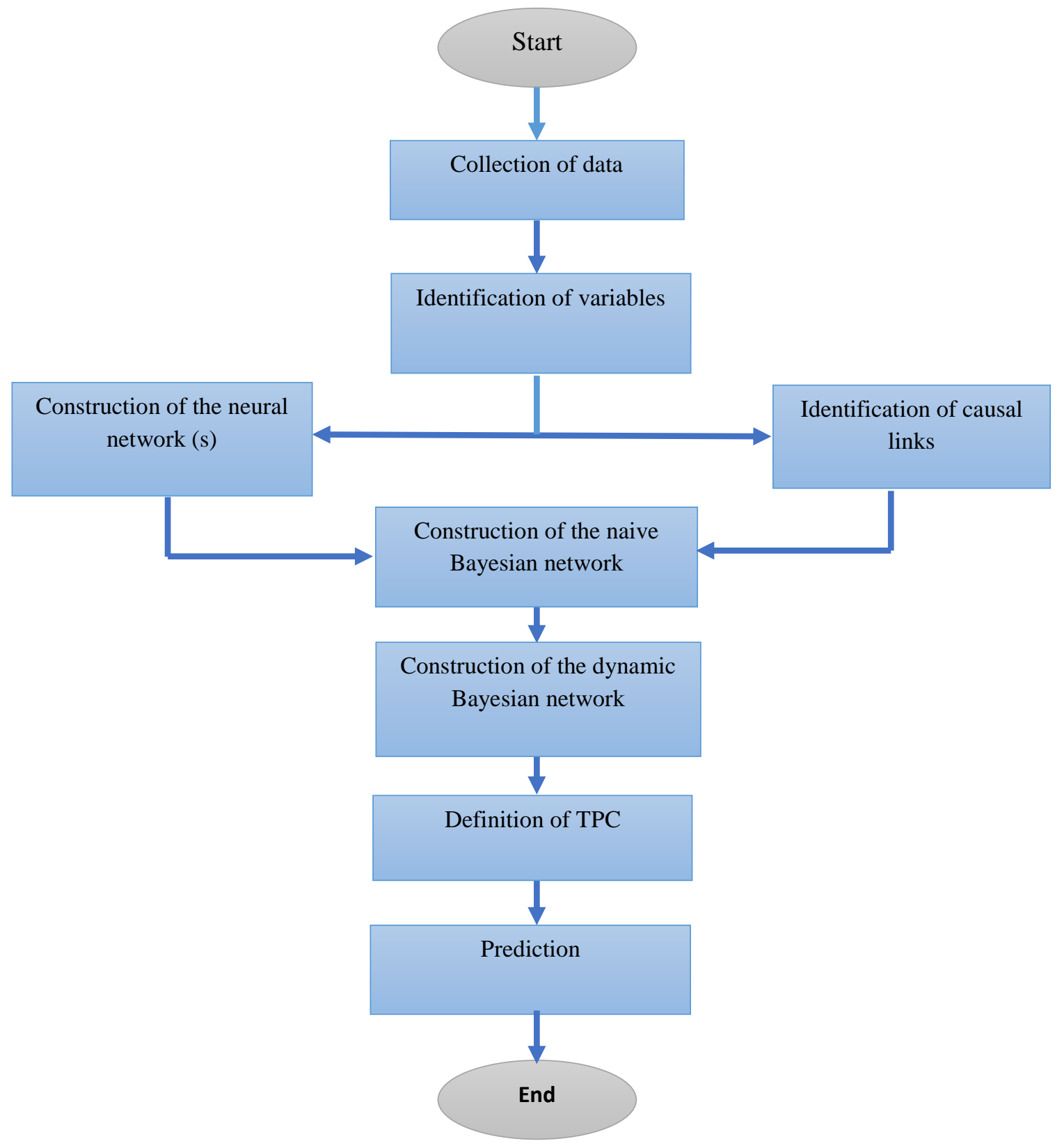

Figure 3: Flowchart applied for our prognosis

- Data collection consisted of a systematic collection of machine data (failure and fault reports, maintenance records, operation data, etc.) and machine component data (on-line data). found mainly in "datasheets" provided by the manufacturer). During this work, a database was created containing 1000 successive observations separated from each other by 20 hours, that is to say a history of 20000 hours of continuous operation.

- The identification of the variables was done to assign to each relevant component a name, a type and a value (or a state for each variable), a threshold (failure indicator). The choice of the type of the variable (discrete or continuous) is important because it allows to determine the type of data associated with this variable (numerical, deterministic or logical), which is very important for the definition of TPC in the Bayesian network.

- The construction of our neural network proper to define the state of system components by analyzing their input parameters.

- The identification of the causal links that link two observed variables at one time (static) or at different times (dynamic).

- The construction of our Bayesian Naive Network (RBN), which is based on Dynamic Bayesian Networks (RBDs) that provide temporal prediction.

- The definition of the conditional probability tables (TPC) which can be the TPC of the "static" nodes obtained from statistical computation (calculation of the Maximum Likelihood), the TPC of the "expert" nodes obtained from expert opinions of the 
machine, finally the TPC of the "dynamic" nodes obtained either from the laws governing the degradation, or from the statistical calculations carried out on a base of knowledge, or from the expert opinion.

The prediction consists in making inferences of the different networks in order to obtain the probability of appearance of the failure at a given moment and under given conditions, and to estimate the RUL of the equipment under precise conditions.

The data used in this work presented in Table 4 are mainly from operations and maintenance services. For the construction of the Bayesian network, the data used are qualitative. This is indeed the history of the states of the system and its components taken with a step of $20 \mathrm{~h}$.

Table 4: Data for Neural Network Construction

\begin{tabular}{|l|l|l|}
\hline Name & Type & Description \\
\hline Temperature & Digital & Temperature in the combustion chamber \\
\hline Knocking & Digital & Knocking in the cylinder \\
\hline MFI & Digital & Opening time of the gas valve \\
\hline
\end{tabular}

\subsection{Construction of the neural network: Perceptron Multilayer}

The construction of a CMP has been broken down into five main steps:

- the input variables and the output variable that undergo, as for all statistical methods, possible transformations, normalizations. In this work, we have as input variables the data coming from Knocking sensors, the data coming from temperature sensors (Temperature) and the opening times of the gas valves (MFI). These are all taken from the last 24 occurrences in order to obtain the state of the component according to its signature and not data taken in a single instant. This makes a total of 72 entries. As for the output, there is one which is the state of the component (Component_State) which can take two states "Normal" or "Abnormal" whose values will be between 0 and 1 .

- The network architecture defines the number of hidden layers that corresponds to an ability to deal with nonlinearity problems, the number of neurons per hidden layer. These two choices directly affect the number of parameters (weight) to be estimated and therefore the complexity of the model. They participate in the search for a good compromise bias / variance that is to say the balance between quality of learning and quality of forecasting.

- The other three parameters that also affect this compromise are the maximum number of iterations, the maximum error tolerated and a possible decay period.

- the learning rate and a possible strategy of evolution of it.

- the size of observation sets or "batches" considered at each iteration.

\subsection{Construction of the Dynamic Bayesian Network}

The problem being that of the prognosis, we used the algorithm MyCaDo (Figure 4), which is a hybrid approach combining the conventional algorithmic approach and the confirmation of the network by an expert to bring out the notion of causality, for the construction of the static Bayesian network. The next step was to learn temporal data and develop temporal knowledge models that are richer than static models. 


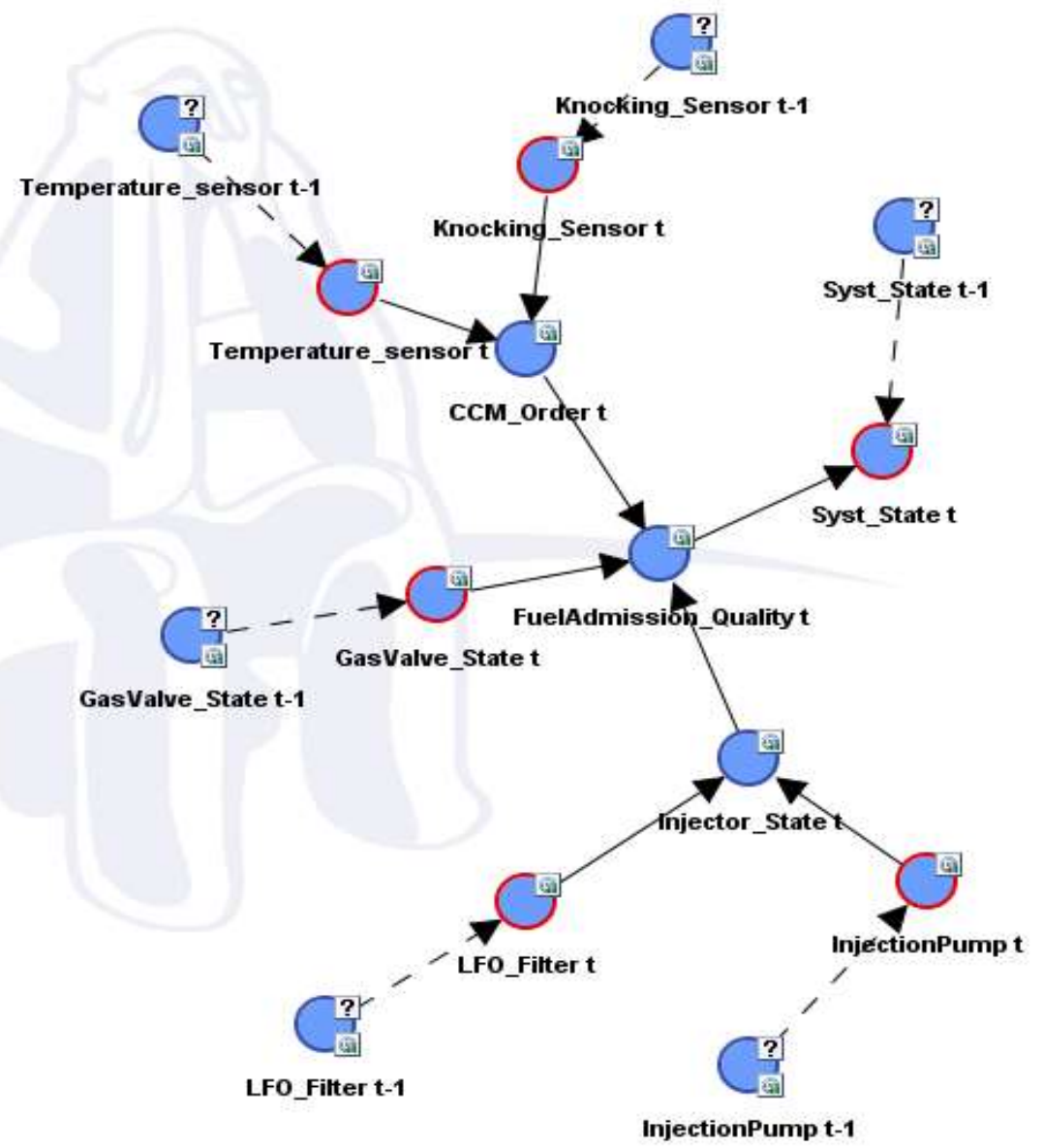

Figure 4: Dynamic Bayesian System Network

\section{RESULTS AND DISCUSSION}

\subsection{Architecture of our neural network}

The architecture of Figure 5 shows the multilayer perceptron consisting of 03 layers, the first called input layer has 72 neurons, the second called hidden layer has 10 neurons and the last called output layer counts 02 neurons.

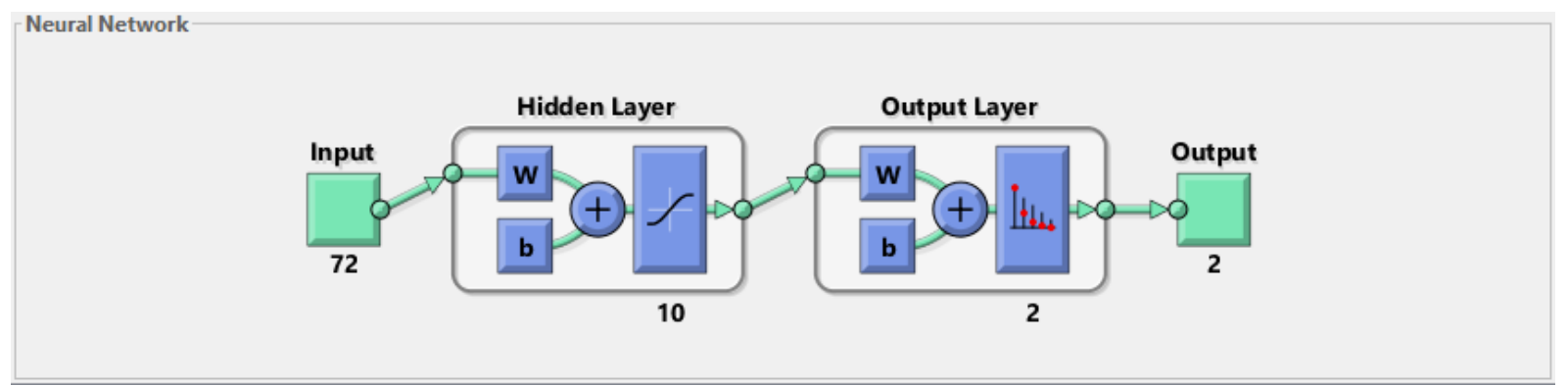

Figure 5: Structure of our multilayer perceptron obtained thans to the toolbox «nntools» of Matlab. 


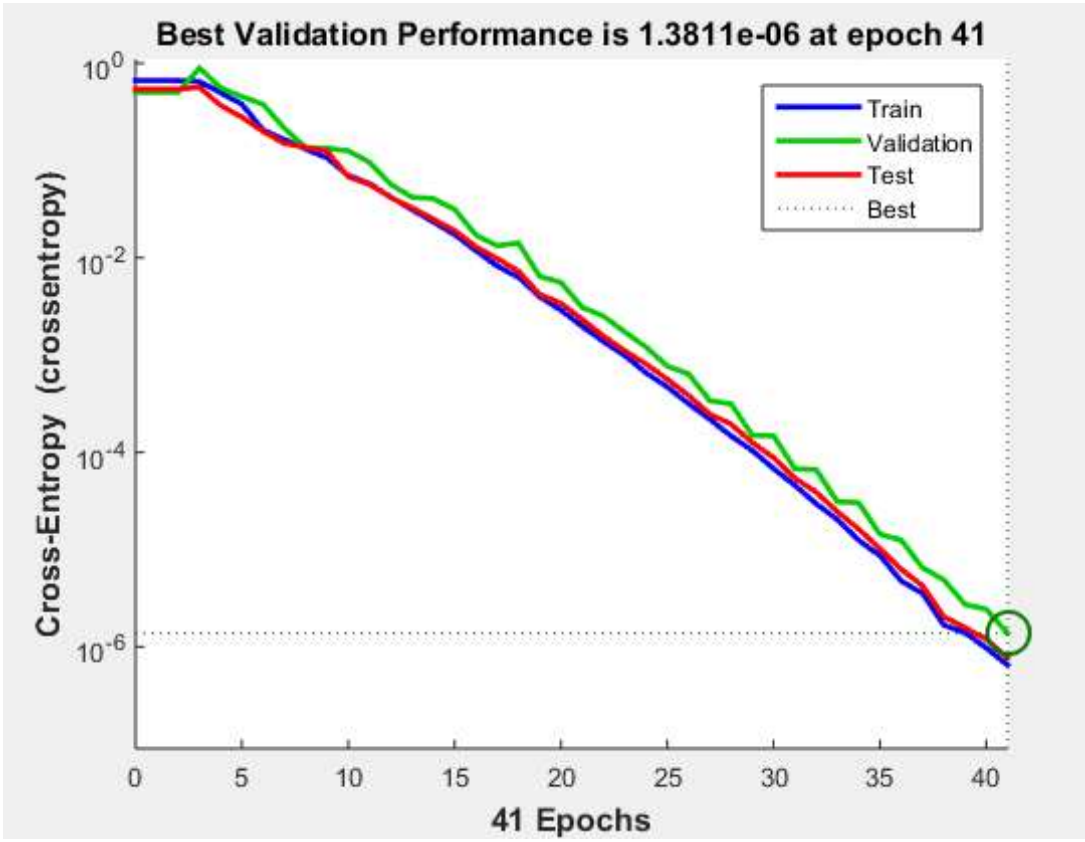

Figure 6: Performance curves of the neural network with cost function cross entropy

The performance curves obtained in figure 6 are decreasing, thus showing that the performances of the system evolve as one advances in learning. In addition, we observe a very close proximity between the learning curves, test and validation, which shows a very well done learning. The confusion matrix shown in Figure 7 (in green and red) is a diagonal matrix. This means that our system correctly classifies its elements and therefore this neural network can be validated.

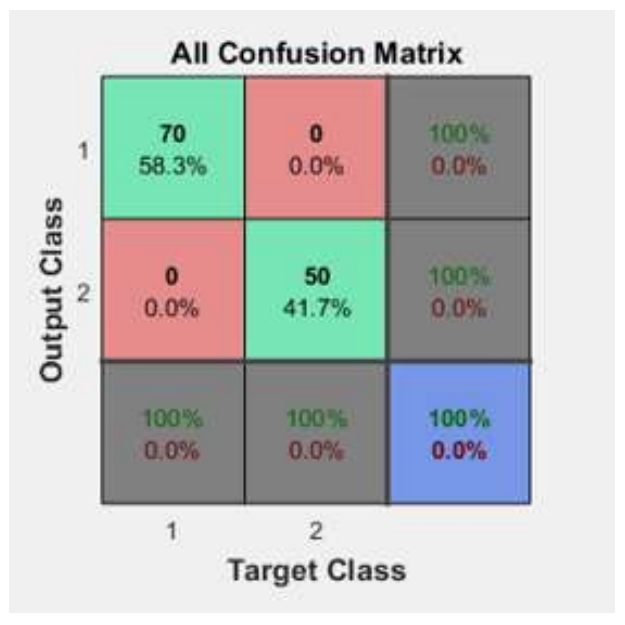

Figure 7: Global Normalized Matrix of Confusion of the Neural Network

\subsection{Presentation of the Human Machine Interface}

The main purpose of the human-machine interface of figure 8 is to facilitate the interaction between our neural network and the user, that is to say to enable a user who does not have advanced computer skills (particularly in programming) to easily use our neural network. In addition, the Human-Machine Interface allows the display of the entered parameters curves (temperature, knocking and MFI) as presented in the WOIS (W18V50DF integrated motor monitoring software) so that the expert can appreciate the adequacy between the state returned by the system and the trends of the curves. 


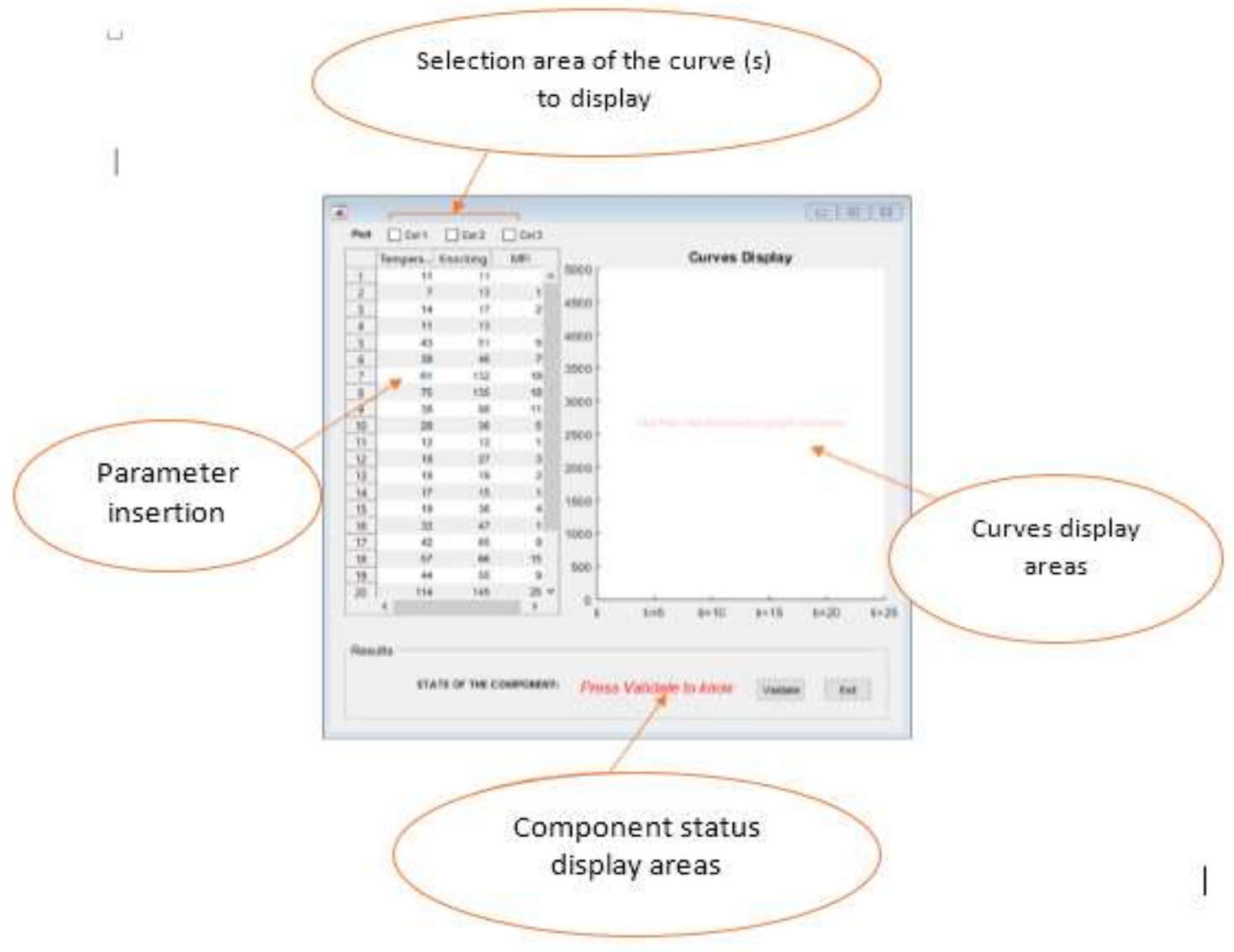

Figure 8: Presentation of the Man-Machine Interface

The three columns of the selection area represent respectively those of Table 4 taken from WOIS in real time. To show or hide their respective curves, just click on one of the buttons Col1, Col2 or Col3. The status of the component is obtained by clicking on the "Validate" button.

\subsection{Prediction curves a priori}

Once this Bayesian network is built, we have a prior knowledge of the system shown in Figure 9. This knowledge is a permanent image of the system studied over a given period. For this prior state of the system we have below the probability prediction curves the "normal" state of the system and the probabilities of the "normal" state of the different components. 


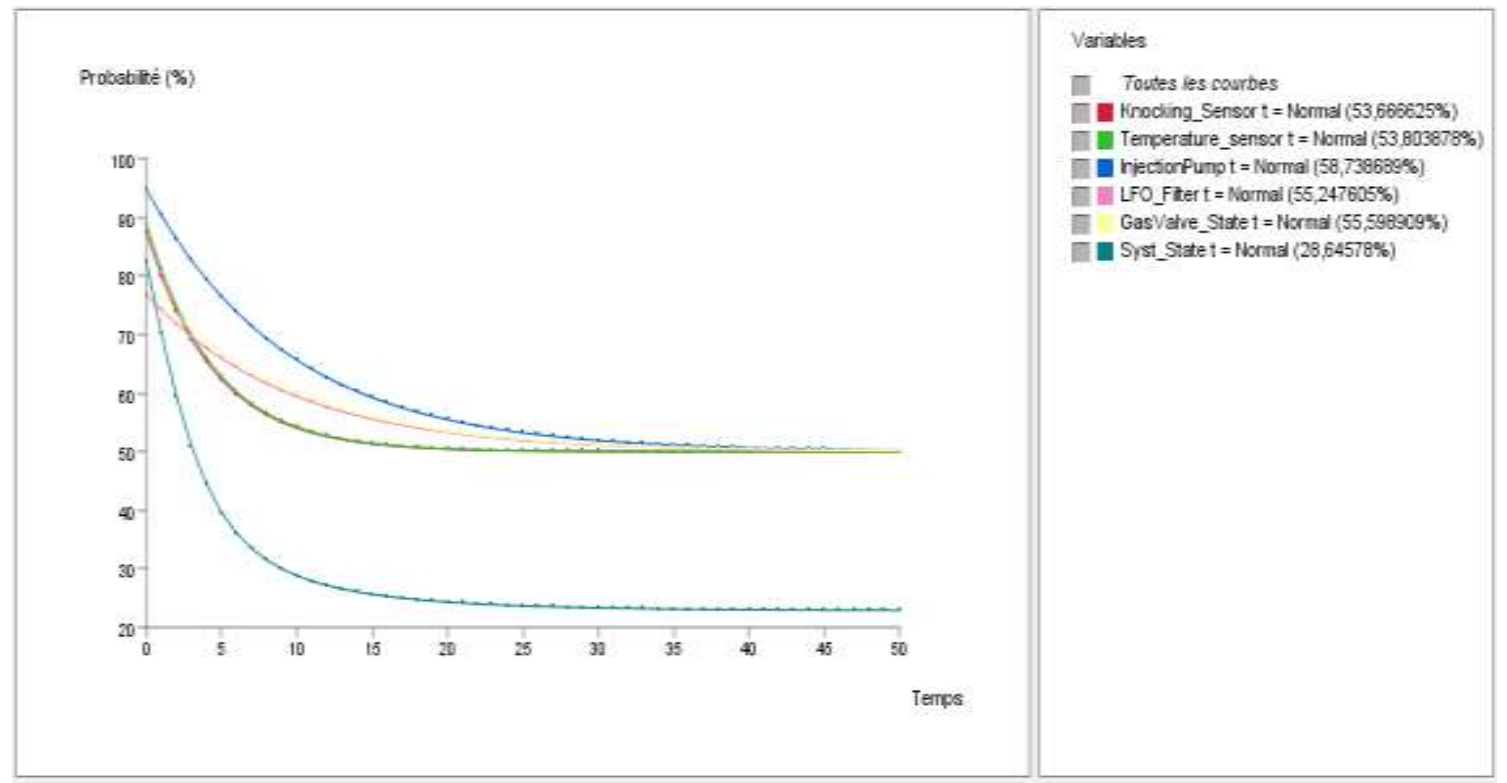

Figure 9: Prediction curve a priori, the time step corresponding to 20h

The finding is made that all these curves are decreasing, which reflects a degradation of the system over time (or life). In addition, the curve has an asymptotic behavior beyond $t_{0}+50$, this is an effect of the structure of our network and consequently of our data set. Which means that this network is capable of making an effective prediction over 1000 hours. In addition, we find that the curve of the variable "Syst_State t" (representing our system) decreases much faster than the curves representing the components of our system. This is due to the criticality of these components and makes the complexity of our system clear.

\subsection{Inference of our Bayesian network}

As the quantitative aspect of the modeling is complete, it is now possible to ask different questions. It's about using inference engines to query the model. Probabilistic inference is essentially a question of calculation. As an illustration, we interrogated the model by asking the following question: $\mathrm{P}$ (SystState $\mathrm{t} \mid$ GasValve_State $\mathrm{t}=$ Normal, Temperature_sensor $\mathrm{t}=$ Abnormal) $=$ ?

The observations here are those of the correct operation of the gas valve "Gas Valve" and the malfunction of the temperature sensor "Temperature sensor" (Figure 10). The use of the Bayes formula makes it possible to calculate the probabilities of all the states of each component of our system following this observation. Thus, the state of our system is defined (predicted) from this calculation of probabilities. The probabilities thus obtained are said a posteriori. 
International Journal of Advances in Scientific Research and Engineering (ijasre), Vol 6 (5), May-2020

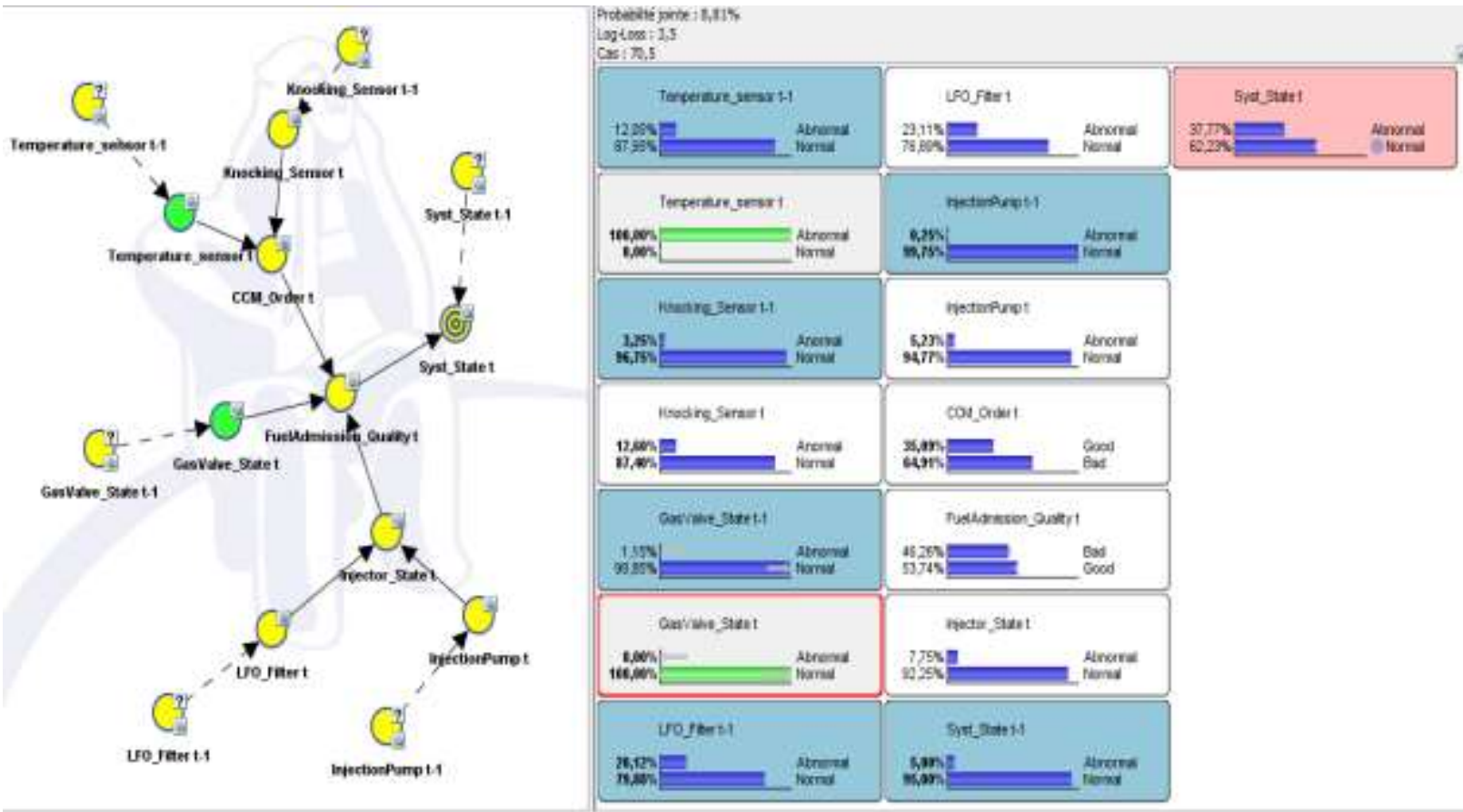

Figure 10: Posterior probabilities of variables

After observing the above observations, it can be seen that the probability that the system in its normal state will go from $\mathbf{8 2 . 4 4 \%}$ to $\mathbf{6 2 . 2 0 \%}$ clearly reflects the significant impact that the temperature sensor has on the operation of our system. Indeed, from a practical point of view, a malfunction of the temperature sensor could cause a false alarm (temperature too low or too high in one of the cylinders for example) and cause the automatic activation of a safety procedure such as stopping the engine very often irreversible until the defect has disappeared.

\subsection{Prediction curves a posteriori}

Knowing a given state of the system, we can proceed to a prediction a posteriori, thus knowing a state a posteriori of our system, one can proceed a prediction a posteriori. For the case evoked (correct operation of the gas valve of the wear of the temperature sensor), it is the prediction curve illustrated in figure 11.

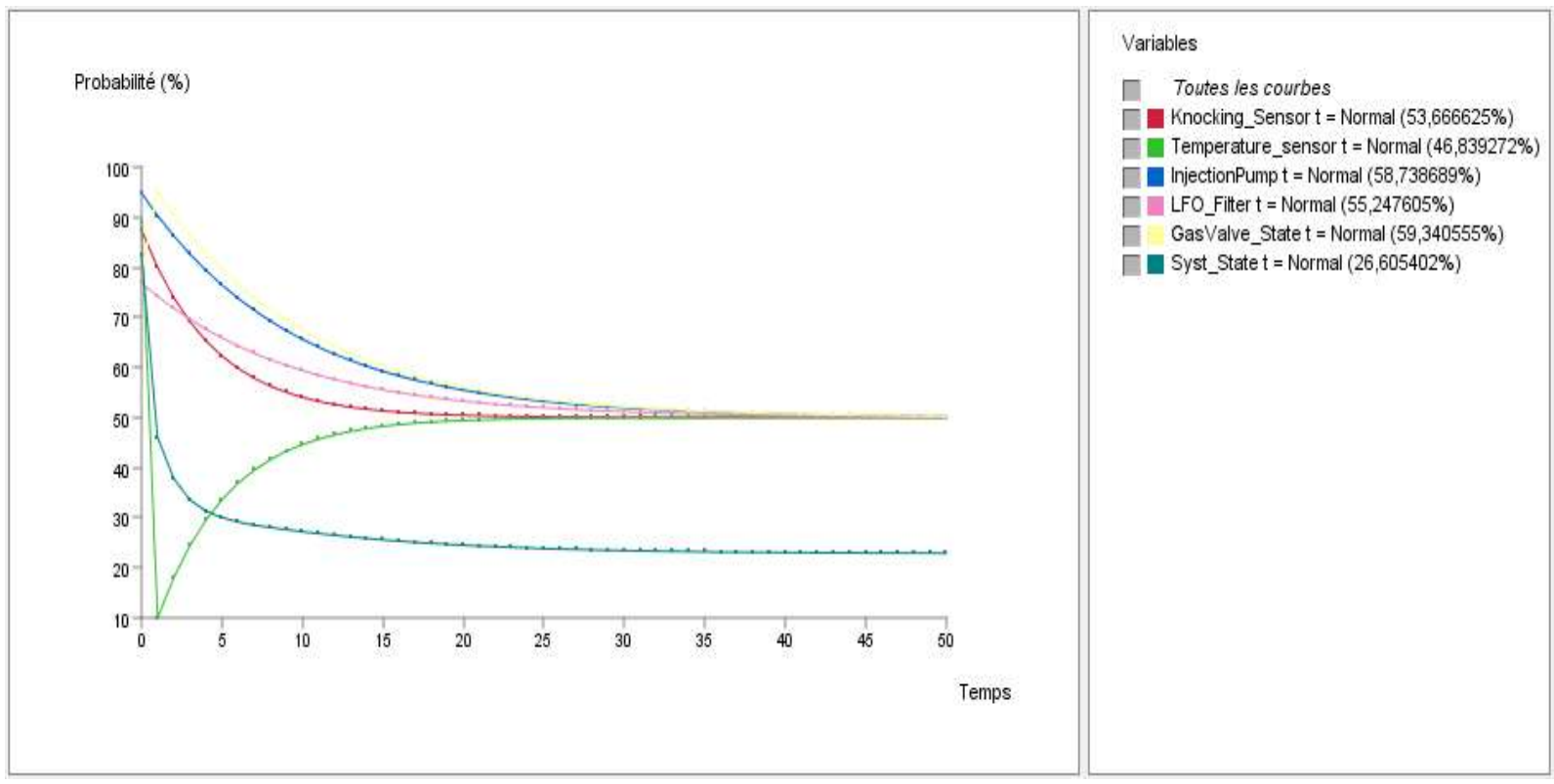

Figure 11: Prediction curve a posteriori, the time step corresponding to $20 \mathrm{~h}$ 
We find that the probability curve of our system in the normal state is always decreasing but decreases faster than the curve a priori. This reflects the fact that under the above conditions (a posteriori) the system is degraded more rapidly. We also note that at $\mathrm{t} 0+50(1000 \mathrm{~h})$ the probability that the system is in the normal state is $26.61 \%$ which is less than $28.65 \%$ (probability that the system is in the normal state) that is, a prediction of an overall decrease in system performance due to the temperature factor. In addition, there is a decrease and then a growth of the probability of normal state of our temperature sensor. This could be explained by the existence of an algorithm (integrated in our system) of automatic readjustment of this sensor. He would have then found a defect of adjustment of the sensor and corrected it.

\section{CONCLUSION}

It was a question here of making the prediction of failures in the W18V50DF engines. The objectives were to highlight the a priori and a posteriori prediction curves, the (probabilistic) evolution of the state of our system in order to anticipate the appearance of a failure and to set up an HMI so to facilitate the handling. To do this, we first realized a state of the art on complex systems, in particular the W18V50DF dual fuels engines and on the methods used for the prognosis of complex industrial systems. Then, the materials and methodology used in this work were presented. Finally, the presentation of the results of this work was made, accompanied by an analysis of these. The work carried out has shown that the W18V50DF engine and its components are degraded as their lifetimes evolve. In addition, it appears that due to its complexity and the criticality of some of its components, the deterioration of the W18V50DF engine will be more accelerated than any of these will be. In addition to this, the financial evaluation not presented here revealed that this work, beyond its multiple technical challenges, would allow the user to realize significant financial gains first of all by producing the expected volume and then $\mathrm{n}$ is not subject to breakage that may cause damage to customers.

In order to improve this work, it will be necessary to deploy the dynamic Bayesian network and set up a human-machine interface to make it easier to use for non-expert use. This will make this work more accessible, even for people with no base in Bayesian networks because the model will be in the background.

\section{REFERENCES}

1. S. A. Abdallah and M. D. Plumbley, "A measure of statistical complexity based on predictive information with application to finite spin systems” Physics Letters A, 2012, Volume 376, pp. 275-281.

2. G. A. Polacek, D. A. Gianetto, K. Khashanah, and D. Verma, "On principles and rules in complex adaptive systems: A financial system case study" Systems Engineering, 2012, Volume 15, Issue 4, pp. 433-447.

3. D. Mourtzis, S. Fotia, N. Boli, and E. Vlachou, "Modelling and quantification of industry 4.0 manufacturing complexity based on information theory: a robotics case study" International Journal of Production Research, 2019, pp. 1-14.

4. V. Modrak, Z. Soltysova, P. Semanco, and P. R. Sudhakara, "Production Scheduling and Capacity Utilization in Terms of Mass Customized Manufacturing” Kinderchirurgie, 2019, pp. 295-306. View at Publisher · View at Google Scholar

5. V. Modrak and Z. Soltysova, "Novel Complexity Indicator of Manufacturing Process Chains and Its Relations to Indirect Complexity Indicators" Complexity, 2017, Article ID 9102824, 15 pages.

6. R. Wang, X. Li, Y. Liu, W. Fu, S. Liu, and X. Ma, "Multiple Model Predictive Functional Control for Marine Diesel Engine" Mathematical Problems in Engineering, 2018, Article ID 3252653, 20 pages. https://doi.org/10.1155/2018/3252653.

7. B. Iung, G. Morel and J. B. Leger, "Proactive maintenance strategy for harbour crane operation improuvement"' Robotica, $\mathrm{N}^{\circ} 21,2003$, pp. 313-324.

8. B. Gille, La notion de "système technique" (essai d'épistémologie technique). Centre de recherche sur la culture technique, Neuilly-sur-Seine (FRA), N¹, 1979, pp. 1-2.

9. Rapport du séminaire ayant pour thème, Les systèmes complexes. 04/02/2018, Museum Toulouse, CNRS.

10. M. Deviart, Architectures de diagnostic et de pronostic distribuées de systèmes techniques complexes de grande dimension, Thèse Toulouse, 2010, $149 \mathrm{p}$.

11. Wärtsilä. (s.d.). WÄRTSILÄ 50 DF Product guide.

12. Dual Fuel Process - Engine on gas, Wärtsilä, [En ligne] [Citation : 04 juillet 2018] https://youtu.be/6mifHJ3MkfE.

13. M. F. Bouaziz, Contribution à la modélisation Bayésienne de l'état de santé d'un système complexe : Application à l'industrie du semi-conducteur, Thèse Grenoble, 2006, 169 p.

14. M. Lebold and M. Thurston, "Open standards for condition-based maintenance and prognostic systems." In Proceedings of the 5th Annual Maintenance and Reliability Conference (MARCON 2001), 2001, Gatlinburg, USA.

15. A. S. Jardine, D. Lin and D. Banjevic, "A review on machinery diagnostics and prognostics implementing condition-based maintenance'” Mechanical Systems and Signal Processing, 2006, Volume 20, 2006, pp. 1483-1510. 
16. A. S. Heng, A. C. Zhang, C. Tan and J. Mathew, "Rotating machinery prognostics: State of the art, challenges and opportunities"' Mechanical Systems and Signal Processing, 2009, Volume 23, Issue 3, pp. 724-739.

17. P. Cocheteux, Contribution à la maintenance proactive par la formalisation du processus de pronostic des performances de systèmes industriels. Thèse de doctorat, Université Henri Poincaré, Nancy I, France, 2010, 162 p.

18. T. Bayes, "An Essay towards solving a Problem in the Doctrine of Chances"' Philosophical Transactions of the Royal Society of London, 1763, Volume 53, pp. 370-418.

19. A. Becker and P. Naïm, Les Réseaux Bayésiens : Modèles graphiques de connaissance. Editions Eyrolles, Paris, 1999.

20. C. Hohmann, « Techniques de productivité : Comment gagner des points de Performance », Éditions d'organisation, 2009.

21. X. Jiang, S. Qin, D. Tong, and L. Wang, “Adaptive Asymptotical Synchronization for Stochastic Complex Networks with Time-Delay and Markovian Switching" Mathematical Problems in Engineering, 2014, Article ID 564058, 7 pages. https://doi.org/10.1155/2014/564058.

22. J. Sun, Y. Shen, and G. Cui, "Compound Synchronization of Four Chaotic Complex Systems" Advances in Mathematical Physics, 2015, Article ID 921515, 11 pages. https://doi.org/10.1155/2015/921515.

23. J. P. Saraiva, B. S. Lima and V. M. Gomes, "Calculation of sensitivity index using one-at-a-time measures based on graphical analysis" in Proceedings of the 18th International Scientific Conference on Electric Power Engineering, EPE May 2017, Czech Republic.

24. E. Chin Lin and T. Supsukbaworn, "Development of Dual Power Multirotor System," International Journal of Aerospace Engineering, 2017, Article ID 9821401, 19 pages. https://doi.org/10.1155/2017/9821401.

25. V. Modrak, Z. Soltysova, P. Semanco and P. R. Sudhakara, "Production Scheduling and Capacity Utilization in Terms of Mass Customized Manufacturing" In: A. Hamrol, A. Kujawińska and M. Barraza, (eds) Advances in Manufacturing II. Lecture Notes in Mechanical Engineering. Springer, 2019, Cham https://doi.org/10.1007/978-3-030-18789-7_25

26. N. J. Beck, W. P. Johnson, A. F. George, P. W. Petersen, B. Van Der Lee and G. Klopp, Electronique fuel injection for dual fuel diesel methane. SAE Paper, $N^{\circ} 900387$.

27. V. Modrak, and Z. Soltysova, "Development of operational complexity measure for selection of optimal layout design alternative,” International Journal of Production Research, 2018, Volume 56, Issue 24, pp. 7280-729596. View at Publisher - View at Google Scholar.

28. R. R. Raine, A performance of the dual fuel (diesel/natural gas) engine. SAE Paper, 1990, N900387.

29. X. Lin, Xiaomei Han, and D. Li, "Design and Evaluation for Target Indicated Torque Based Engine Starting Control Strategy in a High Pressure Common Rail Diesel Engine" Mathematical Problems in Engineering, 2016, Article ID 8216746, 8 pages. https://doi.org/10.1155/2016/8216746.

30. G. H. Abd Alla, H. A. Soliman, O. A. Badr and M.F. Abd Rabbo, "Effect of pilot fuel quantity on the performance of a dual fuel engine" Energy Conversion \& Management, 2000, N41, pp. 559-572.

31. L. Du, F. Qiao, and F. Wang, "Pinning Synchronization of Switched Complex Dynamical Networks" Mathematical Problems in Engineering, 2015, Article ID 545827, 8 pages. https://doi.org/10.1155/2015/545827.

32. W. P. Danyluk, "Development of high output dual-fuel engine”' Transaction of the ASME, 1993, N¹15, pp. 728-733.

33. B. Douville, Ouellette, A. Touchette and B. Ursu, Performance and emisions of a two-stroke engine fueled using highpressure direct injection of natural gas. SAE Paper, 1998, N 981160, pp. 1727-1735.

34. T. Hayasaki, Y. Okamoto, K. AmagaI and M. Arai, A six-stroke DI diesel engine under dual fuel operation. SAE Paper, 1999, N¹999-01-1500, pp. 1-12.

35. V. Drei and G. Mancini, Development of medium-speed and high-speed diesel engine to burn natural gas, biogas and lean gas on stationary plants. SAE Paper, 1990, N 905111, pp. 837-847.

36. G. Grosshans, «Development of a $1200 \mathrm{~kW} /$ cul low pressure dual fuel engine for $\mathrm{LNg}$ carriers », présenté au CIMAC Congress 1998 Copenhagen, 1998, pp. 1417-1427.

37. IFPEN. [En ligne] [Citation : 04 Septembre 2017] https://www.ifpenergiesnouvelles.fr/Actualites/Actualite/Fil-dactu/IFPEN-acteur-en-pointe-dans-le-developpement-des-moteurs-dual-fuel.

\section{LIST OF ABBREVIATIONS AND ACRONYMS}

$\begin{array}{lll}\text { API } & : & \text { Application Programming Interface } \\ \text { CPDAG } & : & \text { Completed Partially Directed Acyclic Graph } \\ \text { EFOF } & : & \text { Equivalent Forced Outage Factor } \\ \text { ENEO } & : & \text { ENErgy Of Cameroon }\end{array}$


International Journal of Advances in Scientific Research and Engineering (ijasre), Vol 6 (5), May-2020

$\begin{array}{lll}\text { GPRS } & : & \text { Gas Pressure Regulation System } \\ \text { GRU } & : & \text { Gas Regulation Unit } \\ \text { GS } & : & \text { Greedy Search } \\ \text { GT } & : & \text { Gas Trip } \\ \text { GT LEGTD } & : & \text { Gas Trip Low Exhaust Gas Temperature Deviation } \\ \text { GUIDE } & : & \text { Graphical User Interface Development Environnement } \\ \text { HFO } & : & \text { Heavy Fuel Oil } \\ \text { ISO } & : & \text { International Organization for Standardization } \\ \text { LDU } & : & \text { Local Display Unit } \\ \text { LFO } & : & \text { Ligth Fuel Oil } \\ \text { MCM } & : & \text { Main Control Module } \\ \text { MLP } & : & \text { Multi-Layers Perceptrons } \\ \text { MyCaDo } & : & \text { My Causal DiscOvery } \\ \text { MFI } & : & \text { Main Fual duration Injection } \\ \text { MLP } & : & \text { Multi-Layers Perceptrons } \\ \text { MN } & : & \text { Methane Number } \\ \text { PdM } & : & \text { Predictive Maintenance } \\ \text { PMB } & : & \text { Point Mort Bas } \\ \text { PMC } & : & \text { Perceptron Multicouches } \\ \text { PMH } & : & \text { Point Mort Haut } \\ \text { PT } & : & \text { Pilot Trip } \\ \text { PT SWL } & : & \text { Pilot Trip Safety WireLoop } \\ \text { RN } & : & \text { Réseau de Neurones } \\ \text { RB } & : & \text { Réseau Bayésien } \\ \text { RBD } & : & \text { Réseau Bayésien Dynamique } \\ \text { RUL } & : & \text { Remaining Useful Life } \\ \text { TPC } & : & \text { Table de Probabilités Conditionnelles } \\ \text { WECS } & : & \text { Wärtsilä Engine Control System } \\ & & \\ \text { MO } & : & \end{array}$

